\title{
Special Issue of Articles Based on the Sixth International Conference on Urban Air Quality, Nicosia, Cyprus 27-29 March 2007
}

\author{
John R. Garratt
}

Published online: 5 March 2009

(C) Springer Science+Business Media B.V. 2009

Air pollution remains a key issue for achieving sustainable development of cities. Our urban areas are continuing to grow in terms of population, transport, energy consumption and utilities. This growth is having local impacts in terms of exposure to high concentrations near streets as well as impacts on regional and global scales including climate change. Consequently, the need for improved understanding of the science of urban air pollution remains a priority for the wider scientific community. Despite improvements in technology, users still require new, robust management and assessment tools to formulate effective control policies and strategies.

With that in mind, the International Conference on Urban Air Quality (UAQ2007) was organised by the University of Hertfordshire and the University of Cyprus, jointly with ACCENT, COST 728, and the Cyprus International Institute for the Environment and Public Health, in association with the Harvard School of Public Health. UAQ2007 brought together scientists and other stakeholders from across the globe to discuss the latest advances in our understanding of air pollution and its impacts on urban areas. The conference as a whole aimed to highlight developments in management strategies and assessment tools for policy and decision makers.

This special issue follows that published in July 2007 (Volume 124, Issue 1), and, in view of the range of topics covered in the articles, continues a trend in Boundary-Layer Meteorology that became clear only a few years ago. This relates to an increasing number of articles published on urban air quality and related topics, including wind-tunnel and large-eddy simulation studies of the urban canopy and street canyon.

Of the 15 articles originally submitted, only six made it to publication-they can be found in the following pages.

John R. Garratt

Co-Editor, BLM

J. R. Garratt $(\varangle)$

CSIRO, Canberra, Australia

e-mail: John.Garratt@csiro.au 